\title{
Erosión de la categoría de sujeto y desmontaje del relato de formación en El Pejesapo de José Luis Sepúlveda ${ }^{1}$
}

\section{Erosion of the character category and dismantling of the formation story in El Pejesapo of José Luis Sepúlveda}

\author{
Carolina Canave \\ Universidad de Chile \\ carolina.canave@gmail.com
}

\begin{abstract}
Resumen
Este trabajo analiza la representación que hace El pejesapo (2007) de José Luis Sepúlveda de la categoría de sujeto popular, en el contexto del denominado cine de la marginalidad. La tesis postula que dicha representación es llevada a cabo mediante el desmontaje de la estructura del relato de formación (bildungsroman), considerado como género emblemático de la cultura moderna. En este relato son constantemente problematizadas las categorías centrales que sustentan el discurso sobre la modernidad tales como progreso, racionalidad, sujeto, entre otras. Esto implica un tenaz cuestionamiento a una forma tradicional de hacer cine a través del rescate de procedimientos que violentan el purismo de ciertos registros, tales como la hibridación del cine directo y la técnica documental, lo cual da como resultado la derogación del "pacto ficcional" al que estamos acostumbrados, tensionando más aún las relaciones entre verdad y ficción.
\end{abstract}

Palabras Clave: Cine chileno, cine de la marginalidad, sujeto popular, relato de formación, modernidad.

\section{Abstract}

This work analyzes the representation that El pejesapo (2007) of José Luís Sepúlveda makes of the category of the marginal popular character, in the

\footnotetext{
1 Este artículo se desarrolla en el marco del seminario "Marginalidad, violencia y ciudadanía en el cine latinoamericano" (2012) dirigido por la profesora Darcie Doll para el programa de Magíster en literatura de la Universidad de Chile.
} 
context of the so called cinema of marginalization. The thesis postulates that such representation is performed through the dismantling of the structure of the formation or learning story (bildungsroman), considered as emblematic gender of modern culture. In this way, in this cinematographic tale the central categories that sustain the discourse on modernity such as progress, rationality, character, among others, are constantly made problematic. This implies a tenacious questioning of a traditional form of making cinema through the rescue of procedures that violate the purism of certain registers, such as the hybridization, the direct cinema and the documentary technique, which gives as a result the derogation of the "fictional pact" that we are used to, straining even more the relations between truth and fiction.

Keywords: Chilean cinema, cinema of marginalization, popular character, formation story, modernity.

En la gama heterogénea de películas que entran en el concepto de "cine de la marginalidad”2 definido por Christian León (2005), se problematizan constantemente las categorías que han sustentado el discurso sobre la modernidad y las ciencias sociales, tales como progreso, razón, sujeto, sociedad o marginalidad. Por esto, un elemento articulador en este trabajo tiene que ver con el contexto de producción cinematográfica de estos largometrajes, en la medida que este tipo de films cuestionan el modo convencional de hacer cine, a través del rescate y puesta en práctica de procedimientos diversos que mezclan la ficción con la técnica documental, lo cual deroga o pone al límite el "pacto ficcional" al que estamos acostumbrados y tensiona las precarias relaciones entre verdad y ficción. Es, en los términos planteados por Darcie Doll (2013), un "'nuevo contacto con lo real' posible de leer como otra forma de relación con lo social. Ello, mediante una serie de estrategias que privilegian una ubicación en las fronteras de los géneros, rompiendo con convenciones naturalizadas" (p. 53).

Otra categoría que podríamos aplicar a esta tendencia cinematográfica sería la de “diferencia” al estilo derrideano, por el desborde evidente que implicala representación, en este caso, de "lo marginal". La diferencia en el fondo es aquello irreductible a la

2 Ejemplos de esta tendencia son Pizza, birra y fasso (1996) de Bruno Stagnaro y Adrián Caetano; Bolivia (2001) de Adrián Caetano: Mundo grúa (1999), El bonaerense (2002) y Leonera (2008) de Pablo Trapero; Silvia Prieto (1998) de Martín Rejtman; La Libertad (2001) y Los muertos (2004) de Lisandro Alonso. En Colombia: La vendedora de rosas (1998), Rodrigo D no futuro (1994) de Víctor Gaviria; La sombra del caminante (2004) de Ciro Guerra; El Colombian dream (2006) de Felipe Ajure; La virgen de los sicarios (2000) de Barbet Schroeder. En Ecuador: Ratas, ratones y rateros (2000) de Sebastián Cordero. En México: Amores perros (2000) de Alejandro González Iñarritu. También están Ciudad de Dios (2002) de Fernando Meireles (Brasil); B-happy (2003) (ChileEspaña-Venezuela), de Gonzalo Justiniano; Tony Manero (2008) de Pablo Larraín 
historia, es lo que queda después de haber desmantelado las portentosas estructuras de la Modernidad para exhibir la diferencia histórica y largamente silenciada bajo su totalidad. Así lo expresa Derrida en su "Carta a un amigo japonés" en donde muestra el gesto estructuralista tras la deconstrucción que, sin embargo, es también un gesto antiestructuralista ya que "se trataba de deshacer, de descomponer, de desedimentar estructuras (todo tipo de estructuras, lingüísticas, "logocéntricas" "fonocéntricas"...”.

Esta derogación de la categoría de identidad se hace extensible en diversos ámbitos culturales. Aplicado al "sujeto", éste es ahora un sujeto descentrado en donde las categorías genéricas, de femenino y masculino, por ejemplo, evidencian sus limitaciones inherentes y no pueden entenderse ya como la autoexpresión de un yo unificado porque sabemos que la identidad es una construcción sustentada a partir de aquellos, y otros pares de oposiciones (que la deconstrucción desmantela) y que no hacen más que evidenciar, como dice Deleuze, la imposición de la fuerza que forjó dichas dicotomías. Para una crítica que se plantea deconstructivamente (de la negación) será ahora precisamente lo negado por las teorías tradicionales, es decir, lo accesorio, lo errante y marginal, lo que adquirirá una inédita relevancia desde el centro mismo de su propia periferia.

Así, en esta nueva tendencia cinematográfica, y en El pejesapo más claramente, lo marginal no es fácilmente simbolizable o categorizable en unidades cerradas, únicas, de sentido. Su significado se erosiona y se nos presenta huidizo, lejano de aquellos estereotipos de lo marginal basados en oposiciones binarias con los cuales estamos tan familiarizados tanto en la pantalla chica como en la grande; tampoco es el sujeto popular como "actor social" en la historia, forjado por el Nuevo Cine Latinoamericano durante los sesenta.

Es en este sentido que podemos hablar de El pejesapo de José Luis Sepúlveda, como un cine que apunta hacia esta diferencia y, por consiguiente, este trabajo busca indagar en aquellos aspectos específicos de la representación de aquella categoría de sujeto marginal que se lleva a cabo en este largometraje y que lo distanciarían de las formas, enfoques o temas propios de la filmografía tradicional ${ }^{4}$ : El Pejesapo es su violencia o lado maldito, su piedra en el zapato, es la representación de la abyección en el cine nacional; es la incomodidad misma de la cultura y la sociedad, su malestar más hondo.

Propongo que la representación de este sujeto marginal cuyo protagonista en El pejesapo es Daniel SS, es llevada a cabo a través de la destrucción y desmontaje de la

3 Ver: $\underline{\text { http://www.jacquesderrida.com.ar/textos/carta_japones.htm }}$

4 Con esto me refiero en general al cine clásico de ficción que, a diferencia de esta tendencia, elide la relación entre el signo y su referencia con el propósito de reforzar la ilusión de su propia autonomía sobre la cual se funda su valor estético. 
estructura tradicional del relato de educación o aprendizaje (bildungsroman), el cual ha sido analizado en profundidad por Bajtín y considerado por críticos como Franco Moretti el género emblemático de la cultura moderna (Citado en Brioso, 2007, p. 36).

Para el caso puntual del protagonista de El pejesapo, la categoría de sujeto tradicional -el de las ciencias sociales pero también el del racionalismo cartesianoes erosionado hasta llegar al punto de su disolución en una serie de metamorfosis camaleónicas, guiadas por el leitmotiv de la "búsqueda" de Daniel SS.

\section{ANTECEDENTES DEL “CINE DE LA MARGINAILIDAD" O "REALISMO SUCIO"}

Marcado por un contexto histórico-social posterior a los regímenes militares latinoamericanos, surge en el continente una nueva tendencia cinematográfica, sobre todo en Argentina, México, Brasil y Colombia. Lo heterogéneo de estas nuevas propuestas, tanto a nivel formal como estético está, sin embargo, cruzado por un rasgo compartido: el retorno a modos de representación que, supuestamente, privilegian un realismo directo en contraposición al afán ficcionalizador o alegórico del cine anterior. Desde el punto de vista de lo representado, estos filmes realizan una crítica abierta a las condiciones de exclusión y marginalización que han traído consigo las políticas neoliberales en el continente, enfatizando en sus consecuencias directas como son la violencia urbana, el desamparo y vulnerabilidad de los sectores más desposeídos de la sociedad.

Respecto de esta reinterpretación y representación de lo marginal llevada a cabo en estas últimas décadas, Christian León en su libro El Cine de la Marginalidad, realismo sucio y violencia urbana (2005) destaca la trayectoria del tema de la marginalidad y sus variadas aproximaciones en el cine, puntualizando que si bien la marginalidad como tema había adquirido interés para los realizadores ya desde las primeras décadas del siglo veinte,

en estos casos no podemos hablar de Cine de la Marginalidad porque este tipo de representaciones, concebidas a partir de patrones del lenguaje cinematográfico clásico y del realismo social, son herederas de la cultura burguesa. Los pobres eran representados desde el lenguaje y los códigos narrativos de la cultura hegemónica, eran vistos desde una mirada exterior que los confinaba a la negatividad del estereotipo o a la positividad de la mirada paternalista (p. 24).

Entre esta visión de la marginalidad ofrecida por estas primeras realizaciones que tematizaron lo marginal, hasta el cambio producido en los sesenta con el Nuevo Cine Latinoamericano, León identifica un quiebre en este tipo de registro, promovido por Los olvidados (1951) de Buñuel en donde se va más allá de la mirada paternalista o 
pintoresca de los sujetos marginales, la cual se despoja de cualquier justificación de tipo moral, lo que inaugura en el cine latinoamericano temas tales como la disolución del vínculo social y la crisis de los valores modernos (p. 25).

En el impulso vanguardista del Nuevo Cine Latinoamericano, a partir de los años sesenta, el cambio en la representación de lo marginal es significativo al pasar de un imaginario del pobre comparado a un niño en su minoría de edad, a una "reinterpretación de la marginalidad social, esta vez a favor de la construcción de sujetos orgánicos, portadores de una cultura nacional políticamente activa”5 (León, 2005, p. 25). De esta manera, las minorías económicas excluidas de la sociedad encarnarían o serían agentes activos portadores de un ideal o destino colectivo del cual son representantes. Esta producción claudicaría abruptamente en los setenta con la instauración de las dictaduras militares en Latinoamérica.

Posteriormente, en los ochenta con el cine brasileño y su estética tropicalista "por primera vez el cine latinoamericano hace una crónica pormenorizada de los procesos de desmontaje de la identidad a la que están sometidos los seres de la calle" (León, 2005, p. 26) a través de una representación inédita del mundo de la prostitución, las drogas y la violencia urbana, como es el caso del filme de Héctor Babenco, Pixote (1980). La película retrata la vida de un niño de diez años que, como tantos en Sao Paulo, deambula por las calles de la ciudad y las favelas, rodeado de violencia, pobreza y miseria. Tanto este tipo de filmografía, junto con las incursiones de Román Chalbaud desde finales de los sesenta y sus intereses sociales, históricos y culturales, más el trabajo realizado a fines de los ochenta por el colectivo peruano Chaski, funcionarían según León (2005), como "filmes de transición entre el Nuevo Cine Latinoamericano y el Cine de la Marginalidad” (p. 27).

\section{CINE DE LA MARGINALIDAD: EL PROBLEMA DEL REALISMO}

El Cine dela Marginalidad es fundamentalmente un fenómeno a nivellatinoamericano que se desarrolla desde los noventa y cuyos antecedentes acabamos de revisar. Esta tendencia de la cinematografía reciente, si bien está abierta a los circuitos masivos, se mueve en los márgenes de todo ese aparato que es la industria cinematográfica local y del llamado "cine de calidad", como sus mismos realizadores le denominan

5 León menciona a connotados cineastas tales como Rocha, Littín, Solanas, Gutiérrez Alea, entre otros. Sin embargo, la crítica posterior a este movimiento se centraría en que esta postura enajenaría de igual modo la singularidad e irreductibilidad de cada uno de estos sujetos, reduciéndolos a un nuevo estereotipo relacionado con la identidad nacional.

6 Con esta denominación me refiero específicamente a las producciones cinematográficas que, a diferencia del cine de la marginalidad o "realismo sucio", se sustentan sobre una búsqueda estética particularísima y de formas más acabadas como lo sería el "cine de autor". 
al posicionarse deliberadamente en su periferia. A pesar de toda la variedad de expresiones que pueda reunir esta tendencia, lo transversal a esta diversidad radica en ofrecer una imagen, una representación del sujeto marginal y su entorno, pero desde otras bases y consideraciones formales que optarían por suprimir lo más posible las mediaciones que necesariamente intervienen en la instancia de su representación cinematográfica.

Una de estas mediaciones que el Cine de la Marginalidad pretende suprimir es la intención por parte de ciertos autores no solamente de hablar de lo marginal sino de querer ofrecernos una "interpretación" sobre lo marginal, subsidiaria de los códigos de cultura burguesa, lo cual no está exento de lugares comunes y representaciones estereotipadas, propias de ciertos géneros cinematográficos como son el melodrama o la comedia y que datan de principios del siglo pasado.

Así como no es lo marginal basado en estereotipos tampoco es lo marginal como alegoría. Los sujetos del "cine de la marginalidad", "realismo sucio" o "nuevo realismo", como se ha dado en llamar a esta tendencia actual, no son representaciones alegóricas, por ejemplo, de la decadencia de un sistema o un país, sino que son "figuras que sin detenerse en el zócalo de la alegoría, condensan materiales extraídos de un paisaje en ruinas y se construyen sin una dirección precisa entre novedad y tradición, entre la zozobra de las pérdidas y el optimismo del sobreviviente” (Amado, 2003, p. 53).

Por lo tanto, lo central de estas nuevas tendencias cinematográficas es la representación de la realidad lo más alejada del verosímil cinematográfico que ha primado en los circuitos oficiales, tal como lo ha planteado Christian Metz (1970). Él se pregunta por la decadencia o no de un verosímil que finalmente es el que rige la adopción de ciertos temas por sobre otros, en función no de todos los "posibles" sino de aquellos ciertos posibles verosímiles, que siguiendo la categoría aristotélica, son tales en la medida que se desarrollan conforme a la leyes de un género dado ${ }^{7}$. Esto sería lo que Metz asocia con la "censura ideológica".

La pregunta que surge entonces podría plantearse en los siguientes términos: ¿Cuál es el verosímil que entra en decadencia con el cine de la marginalidad? ¿Acaso es posible hablar con esta nueva tendencia cinematográfica de la apertura de un nuevo verosímil?

Los géneros, no sólo los cinematográficos sino los géneros del discurso en general, son sistemas históricos que regulan las prácticas mismas; es decir, definen sus límites o lo que "son" en relación a otros discursos, ya sea por comparación, contraste, etc. En relación al tema de este trabajo, como veremos, los recursos formales utilizados

7 Lo verosímil es así en función del género al que pertenece: western, filme policial, comedia dramática, etc. "Cada género tenía su campo de lo decible propio y los otros posibles eran allí imposibles" (Metz, 1970, p. 20). 
en El pejesapo no son arbitrarios sino que están directamente relacionados con lo que se desea representar. Uno de estos recursos, que por lo demás es transversal a las producciones vinculadas al cine de la marginalidad y a las prácticas modernas, es la trasgresión o la exhibición de lo "fronterizo" de estas convenciones genéricas: lo documental, por una parte, lo ficcional, por otra. Esto es claramente lo más significativo de estas propuestas ya que

la productividad de este conjunto de filmes $[. .$.$] se juega en la necesidad de conservar$ 'visible', para apreciar su productividad de sentido, el 'carácter fronterizo' entre registros, entre circuitos de circulación, entre lo nuevo y lo antiguo, entre el arte y el discurso televisivo, entre la verosimilitud y 'la verdad de la imagen', no 'la imagen verdadera' (Doll, 2013, p. 54).

Este entrecruzamiento o posicionamiento fronterizo se da a nivel del formato o género visible al cual recurre el largometraje (ficción y documental), pero también en la relación actor-personaje, en donde estas dos funciones tienden a confundirse y mezclarse. Por ejemplo, esto sucede en otros filmes de esta misma tendencia como son Mundo grúa, en donde Luis Margani, actor natural, hace de "Rulo", personaje que se da a prender el manejo de una grúa con el fin de conseguir trabajo y cuyas características e incluso datos de su biografía coinciden con los de Margani.

En el cine de Víctor Gaviria, como en La vendedora de rosas, los personajes son construidos a partir de actores naturales, generalmente niños de la calle, drogadictos o sicarios, que sobre la base de sus testimonios de vida, ayudan a elaborar el "guión". La misma protagonista de la película, Leidy Tabares, actriz natural, se encuentra actualmente en prisión por el delito de hurto y homicidio.

Otra característica de este tipo de cine, que llega al paroxismo en el ejemplo anterior, es la utilización de un tipo de lenguaje propio de los sociolectos marginales que rompe radicalmente los códigos lingüísticos con los cuales estamos familiarizados. Como lo ha analizado Darcie Doll (2013), "esta estrategia llega incluso a la imposibilidad de reconocer el léxico, evidenciando una suerte de incompetencia auditiva por parte del espectador, que procede a romper la ilusión de realidad comprometida en los códigos que apuntan al deseo de naturalización del cine comercial" (p. 56).

$\mathrm{Si}$ bien el verosímil que ha prevalecido de manera hegemónica en las representaciones de diversa índole desde el siglo XIX en adelante ha sido denominado

8 Las comillas apuntan a relativizar el concepto debido al alto grado de improvisación del cual se nutren estos filmes. Será el mismo Gaviria quien apunte al "carácter coautoral de sus películas, en la medida en que son los propios actores quienes colaboran determinando 'lo que se dice' 'más que lo que debe decirse' ante una situación determinada" (Ruffinelli, 2009, p. 25). 
genéricamente como "realismo" (Follain de Figueiredo, 2009), podemos, sin embargo, puntualizar que este mismo concepto está sujeto a variaciones históricas en función de lo que para cada época responde a dicha clasificación. No es lo mismo el realismo decimonónico de un Balzac o las exploraciones entorno al realismo realizadas en el siglo XX con el denominado "realismo social" o neorrealismo en literatura, pintura o cine, que el "nuevo realismo" al cual refiere Follain de Figueiredo y que sería a la cual recurre esta nueva tendencia.

En torno a esta discusión teórica sobre estos nuevos realismos en los medios, debemos agregar que el paso de una instancia a otra no es un continuum que se sucede de manera progresiva o natural. Recordemos el quiebre que significó en este supuesto tránsito la "crisis de la representación artística" o del arte de narrar, desencadenada tanto por los traumas históricos como por la borradura de la experiencia llevada a cabo por la reproducción en serie del capitalismo augurados por Benjamin. En este sentido, frente a esta crisis de la representación experimentada por las artes, desde el cine parece provenir una tentativa de solución o por lo menos una vía de escape a ese callejón sin salida que era la pregunta por cómo narrar después de. Esa tentativa de respuesta estaría en estos "nuevos realismos" explotados, entre otros discursos, por el Cine de la Marginalidad y que se caracteriza porque "abdica se de qualquer pretensão de universalidade, assim também como se renuncia à pretensão de falar pelo outro" (Follain de Figueiredo, 2009, p. 33).

En este sentido, el "nuevo realismo" sería una respuesta o consecuencia de la caída en descrédito de los relatos con pretensiones universalizantes (metarrelatos para Lyotard) que intentaban dar un sentido a la marcha de la historia. Por lo tanto, este "nuevo realismo" a diferencia de las corrientes realistas precedentes, sería un fenómeno claramente posmoderno en el sentido de que defiende la hibridación, la cultura popular, el descentramiento de la autoridad intelectual y científica tanto como la desconfianza ante los grandes relatos.

En los aspectos formales de esta nueva tendencia o "nuevo realismo" como le llama Follain de Figueiredo, la apuesta está en un alejamiento del esteticismo y despreocupación por las formas artísticas acabadas. Las instancias intermediarias entre el público y la producción cinematográfica son reducidas a su mínima expresión, privilegiándose el registro directo y la técnica de tipo documental, donde ya nadie habla por el subalterno sino que es él quien habla por sí mismo, lo que pone de manifiesto, sobre todo desde la cultura brasileña actual, una especie de "cruzada contra el artificio en las artes" (Follain de Figueiredo, 2009, p. 35). Con

9 Las representaciones que escapan a la normativa hegemónica del realismo tales como la ciencia ficción o lo fantástico, siempre han permanecido en un nivel más excéntrico, al considerarse como "géneros menores". 
esto se da la tendencia a valorizar, actualmente, a aquellas narrativas que privilegian la representación de un "real auténtico" supuestamente sin mediaciones, lo que ha llevado a hablar de una crisis de la ficción. Esta cruzada contra el artificio en las artes es un fenómeno generalizado en Brasil y que se ha hecho extensible a países como Colombia, Perú, Argentina y Chile. Los recursos utilizados, sobre todo en las artes que usan la imagen como soporte, es la del sujeto que se representa a sí mismo, en donde la duración se confunde con el tiempo de la experiencia retratada y donde no hay la presencia de un guion definido.

Sin embargo, tales procedimientos no necesariamente anulan el carácter subjetivo y retórico del trabajo del montaje cinematográfico, su puesta en escena, ya que el hecho de colocar una cámara de filmación ya es, de alguna manera, la ficcionalización de dicho acontecimiento. Por lo tanto, esta ideología de no intervención del llamado "cine directo", se revelaría, según Figueiredo, tan ilusoria como la presunta objetividad del realismo tradicional.

Por su parte, Ana Amado (2002) considera que no son siempre viables las distinciones binarias del tipo realismo/no realismo ya que

más allá de su oportunidad, las cartografías que sitúan a estilos y autores en un lado u otro de la ecuación 'realismo-artificio' pierden contundencia cuando se admite que el cine es antes que nada registro y reproducción, que entre las virtudes de su dispositivo material está la de captar lo real, llegar de entrada a lo sensible (Amado, 2002, p. 87).

En este sentido, la oposición entre estos dos términos de debate se diluiría, ya que en el arte cinematográfico el "registro" no se opone la formalización de la "puesta en escena” y a sus procedimientos de construcción.

Según León (2005), los antecedentes de estos procedimientos formales y generalmente de bajo presupuesto con los que trabaja el Cine de la Marginalidad, se remontarían a la "estética del hambre" formulada en los setenta por el cineasta brasileño Glauber Rocha y las técnicas documentales del cinéma vérité (León, 2005, p. 28).

Ahora bien, desde el punto de vista de sus temas, esta nueva tendencia, al iniciarse con el fin de la épica de los movimientos de liberación nacional y en plena crisis de los discursos contestatarios y utopistas, se opone o

plantea una ruptura con los objetos, los temas y los conceptos, y el tipo de enunciación que caracterizó al Nuevo Cine Latinoamericano [... Respecto a los temas, busca problematizar la vida en las grandes ciudades, la corrupción de los valores, la crisis de la identidad, la marginalidad y la indigencia. Frente a las grandes temáticas históricas, políticas y cívicas que caracterizaron al Nuevo Cine, apela a la micropolítica del cuerpo, la cotidianidad y la calle. Ciertamente en los setenta como en los noventa, en el cine latinoamericano existió una presencia generalizada de sujetos subalternos 
rodeados de pobreza, violencia y discriminación $[\ldots]$ sin embargo, la miseria y subdesarrollo construidos por el Nuevo Cine estaban iluminados por una confianza en los valores modernos amparados bajo conceptos como pueblo y nación, mientras que el realismo sucio enfoca estas mismas tópicas desde la realidad cotidiana y corporal de seres excluidos de la institucionalidad moderna (León, 2005, pp. 30-31).

En este apartado he querido aproximarme a esta tendencia denominada "cine de la marginalidad” desde dos de sus flancos, que por lo demás están estrechamente vinculados entre sí. Por una parte, está el tema que básicamente se centra en la representación de ciertos sectores marginados por las políticas neoliberales instauradas en Latinoamérica en las últimas décadas. Este sujeto popular-marginal, sin embargo, no es representado ni desde el estereotipo de lo popular ni desde la alegoría social. Por otra parte, encontramos que una de las características definitorias, y que daría cierta unidad a este corpus de obras más bien heterogéneas y de diversa índole, está dada por sus recursos de producción, que de manera deliberada tensionan el purismo de los géneros, en este caso el documentaly la ficción, lo que trae al centro del debate el problema respecto del "realismo". Desde esta perspectiva, la productividad de estos filmes estaría dada no por ceñirse a uno u otro registro -oposiciones que, como indica Amado, no serían pertinentes en el arte cinematográfico- sino que su autenticidad estaría precisamente en su carácter fronterizo y móvil que llevado al plano de la representación del sujeto "fractura la antropologización del sujeto marginal y su representación 'latina' o imaginario de exportación, al situarse entre lo uno y lo otro y escamotear la fijación” (Doll, 2013, p. 57).

En El pejesapo, como veremos, este recurso formal, híbrido y fronterizo da cuenta de una categoría de sujeto también móvil cuyo significado se erosiona al punto de diluir la noción de identidad como categoría esencial.

\section{EL PEJESAPO: EROSIÓN DE LA CATEGORÍA DE SUJETO Y DESMONTAJE DEL RELATO DE FORMACIÓN}

Dadas las características recientemente mencionadas para definir al Cine de la Marginalidad, consideramos el filme El Pejesapo como representativo de esta tendencia; es decir, de un cine que se asume a sí mismo distanciado de toda pretensión de perfección y cuya fuente de apropiación es ante todo la precariedad. Para hacernos una idea del desconcierto e incomodidad que este tipo de largometrajes suele provocar, basta recordar el Festival de Cine de Valdivia en octubre del 2010 el cual había dedicado un espacio a los realizadores chilenos José Luis Sepúlveda y Carolina Adriazola con una muestra que contemplaba la proyección de seis obras, ciclo que fue, en último minuto, suspendido, "argumentando que los films recibidos no 
cumplían 'con el formato correspondiente al estándar técnico que se requiere para este tipo de eventos'” (Montero y Valdebenito, 2012, p. 99). En relación sobre todo a este punto, que insiste en que este tipo de producciones adolecerían de los estándares técnicos necesarios para participar en un festival como el de Valdivia, son sus mismos realizadores quienes se defienden al enfatizar que la idea a priorizar es precisamente la adopción de "la precariedad como forma de expresión, rechazando el preciosismo estético. Para estos realizadores, la calidad técnica es sinónimo de un presupuesto holgado que obliga a transar la postura ideológica de la obra y, que por lo tanto, está fuera de sus intereses" (Montero y Valdebenito, 2012, p. 100).

Héctor Silva, el actor que representa a Daniel SS, es actor pero formado en talleres realizados en su reclusión carcelaria por asaltar a un taxista. El resto de los actores son en su mayoría actores naturales y cuyas experiencias de vida han contribuido de una u otra manera a darle forma al guión.

En ellargometraje El Pejesapo, con una imagen desprolija, de corte directo y cámara en mano, se rompe el pacto ficcional al mezclar los registros ficcionales, documentales y la entrevista. Nos encontramos así con distintas situaciones que nos permiten reconstituir en su secuencia temporal, una especie de relato pero fracturado, lleno de vacíos, que nos muestra la vida y "avatares" de Daniel SS; un ex convicto, adicto a la pasta base, quien yace semidesnudo, al comienzo del filme, en el lecho del río Maipo tras un intento de suicidio. El suicidio, desde un punto de vista interpretativo, como una especie de descenso a los infiernos y el simbolismo del río, marcarían el punta pie iniciático de la peregrinación y búsqueda del personaje.

A partir de aquí, y tras ser rescatado por un arriero desde el río, Daniel SS inicia una especie de peregrinación errática por distintos lugares 10 que van desde la ribera del río Maipo, desde la precordillera, al centro de la ciudad, deambulando por poblaciones, arrabales y circos de travestis; para tratar, sin mucha convicción ni entusiasmo, de restituirle algún sentido, por precario que sea, a su existencia o experimentar algún sentimiento que pueda apartarlo de reincidir nuevamente en el suicidio.

En este trabajo se plantea que este largometraje desmantelaría la estructura tradicional del relato de formación en su sentido tradicional. Primero que nada, está claro que Daniel SS no es un adolescente que está recién explorando el mundo como en la mayoría de los relatos de formación, sino que ya "viene de vuelta", lo cual es también parte de la inversión de este tipo de relato. Sin embargo, al ser rescatado o más bien expulsado por el río y no morir ahogado, se le presenta la oportunidad de redescubrir la realidad, algo que intuye precariamente dándose a la tarea de buscar - como sabiendo de antemano su fracaso- si hay algo por lo que valga la pena vivir.

10 Se aloja en la ribera del río donde lo alojan una pareja de ancianos; trabaja como cantero sacando piedras del río, luego se ve en una casa deshabitada junto a un amigo fumando pasta base. 
En la novela de educación, como le llama Bajtín (1995)11 a este tipo de relato, se presenta un héroe en desarrollo, como una unidad dinámica, que es tan variable como su carácter. El argumento se ve influido y determinado por las transformaciones que sufre el sujeto, que a su vez se ve influenciado por su tiempo, cambiando la importancia de los momentos de su vida y su destino.

Por otra parte, si seguimos a José Santiago Fernández (2002) debemos indicar que el bildungsroman es el relato de una cultura que busca describir la entrada en la madurez social de sus miembros más jóvenes, es decir, "es una descripción de cómo debería tener lugar este proceso si concurriesen las circunstancias que se dan habitualmente en esta clase de relato" (p.47). La historia de Daniel SS se nos presenta desde el reverso de este proceso, como su resultado fallido, lo cual revela que no se cumple para todos dicho proceso de maduración social en el cual dejamos nuestro estado transicional (la adolescencia) para configuramos como identidades fijas (el adulto).

Siguiendo tanto a Bajtín (1995) como a Fernández (2002), tenemos que otra característica del relato clásico de formación es el motivo del viaje. El héroe se desplaza y en este caso esto se cumple en un desplazamiento que va desde el campo o la precordillera a la ciudad, y del centro de la ciudad a sus márgenes: la población y el arrabal.

Vinculado directamente con el viaje está la búsqueda. Pero esta tentativa de búsqueda tan propia y característica del relato de formación o aprendizaje -donde el protagonista o héroe se busca a sí mismo o al destino que le es propio en el cual pueda realizar o concretar su integridad física, moral o psicológica- es la que en El pejesapo se revela como fallida: no hay para el protagonista conciliación alguna entre individuo y la sociedad o su entorno microsocial, lo que sería el fin último del tradicional relato de formación. Este tipo de relato ha sido considerado por críticos como Franco Moretti el género emblemático de la cultura moderna. (Brioso, 2007, p. 36). El Bildungsroman es descrito por Moretti como la forma simbólica que, más que ninguna otra, ha retratado y promovido la modernización social, por lo tanto

si se acepta la tesis de Moretti, a este género le es inherente una peculiar concepción del espacio social, la cultura y la política, y su énfasis radicaría en el fortalecimiento y continuidad de un status quo más que en su subversión o revolución. El Bildugsroman pertenecería al bando girondino del espíritu ilustrado, que busca promover soluciones

11 Al respecto Bajtín indica: "El hombre se transforma junto con el mundo, refleja en sí el desarrollo histórico del mundo. El hombre no se ubica dentro de una época, sino sobre el límite entre dos épocas, en el punto de transición entre ambas. La transición se da dentro del hombre y a través del hombre. El héroe se ve obligado a ser un nuevo tipo de hombre, antes inexistente [...] Se están cambiando precisamente los fundamentos del mundo, y el hombre es forzado a transformarse con ellos" (1995, pp. 214-215). 
contractuales para los conflictos entre individuo e historia. El Bildugsroman es el género antiutópico por excelencia (p.36).

Sería, en este sentido, un intento por establecer una relación contractual entre la norma y la trasgresión, entre la ley y el deseo, lo que no se puede llevar a cabo en el personaje de Daniel SS. Luis Mora se refiere a lo mismo pero en otros términos cuando diferencia el cine perfecto del imperfecto. En el primero, la

ideología que le da consistencia a todos estos componentes es el pre-supuesto de que todo lo que se narra lleva necesariamente a una conclusión única e inevitable. Por lo tanto, la visión de mundo propuesta en este cine perfecto es la de llevar al protagonista $-\mathrm{y}$ a los espectadores- al reconocimiento de una verdad o de su verdadera identidad, hasta entonces oculta (Mora, 2011).

En este filme no se busca la justificación moral de Daniel SS y la marginalidad que lo envuelve no está mediada por complacencias de ningún tipo, ni tonos paternalistas. Al contrario, el cinismo y el carácter claramente manipulador que el personaje hace de su situación ${ }^{12}$, lo hace más bien un tanto despreciable, por lo tanto, no hay simpatía ni identificación por parte del espectador con este sujeto. Como dice Luis Mora, en El Pejesapo, la mirada sobre la sociedad "se da desde el cinismo de un delincuente que sobrevive como un camaleón y cambia sus afectos de acuerdo a su circunstancia” (2011). No hay "aprendizaje" ni "acuerdo" por sutil que sea entre los deseos y la normatividad, sólo una movilidad camaleónica que nos trae una vez más a escena las tretas utilizadas por el débil, de las que nos habla Ludmer. Y esto es así porque hemos realizado a lo largo de la historia contratos sociales que supuestamente garantizan la heterogeneidad e integración de todos los sectores de la sociedad, pero que finalmente evidencian sus limitaciones, fisuras y grietas a través de personajes como Daniel SS y todos los demás sujetos nunca tocados por las supuestas bondades del sistema económico y por de las políticas integradoras del Estado.

Para Max Weber, el concepto de sociedad se entiende como una serie de interacciones regidas a "una racionalidad con arreglo a fines" (León, 2005, p. 40) que, sin embargo, no es suficiente para dar cuenta de comportamientos supuestamente irracionales y que, por lo tanto, no se ajustan a la racionalidad ilustrada promovida por el discurso de la modernidad y sus valores universales: "este desajuste entre el discurso universalista de la racionalidad letrada y las expresiones contraculturales de los colectivos subalternos produce que determinadas franjas del espectro social

12 En una de las situaciones en que Daniel SS está con su esposa, ésta le reprocha sus tendencias suicidas, ya que lo habría encontrado colgándose en la entrada de la vivienda, a lo que él responde que no le quedó otra ya que lo dejara entrar. 
sean intraducibles al lenguaje clásico de las instituciones modernas y de las Ciencias Sociales" (León, 2005, p. 41).

Es, si se quiere, este excedente en la sociedad lo que es Daniel SS; aquello irreductible a ser sistematizado ya que la categoría misma de sujeto, entendida en el sentido moderno del término como ser racional, portador y fuente de significación, ha erosionado hasta convertirse en una categoría vacante que puede ser llenada, improvisada, de acuerdo a las circunstancias del momento: ex convicto, suicida, cantero, asesino, "angustiado", padre a medias, esposo de una mujer con parálisis facial, amante de un travesti de circo o trabajador explotado de una planta de reciclaje cuyo aval político es nada más y nada menos que Luisa Durán de Lagos ${ }^{13}$. Este último punto contribuye más aún a enfatizar este carácter fronterizo de la historia, instalándola en el intersticio de lo real/ficticio al entregar las únicas coordenadas temporales históricas precisas a lo largo del relato y que le sirven de marco: el gobierno de la Concertación, específicamente el de Ricardo Lagos. Pero por otro lado, esta fugaz aparición contribuye a la crítica tajante de la clase política chilena mediante su vinculación con empresarios sin escrúpulos que esgrimen fines sociales y ecológicos como motivación principal para su "emprendimiento".

Después de que es rescatado del río, Daniel SS tiene la intención de quedarse a vivir con una familia de ancianos, que al parecer lo acogen temporalmente, los cuales viven en los alrededores del río. Sin embargo, es finalmente rechazado y esta primera parte se cierra bruscamente con una escena confusa en donde el protagonista está apuntando con una escopeta al anciano, mientras que la anciana habla sobre la muerte, su muerte. Se oye un disparo seco. Inmediatamente después la escena cambia y vemos a Daniel SS en el trasporte público rumbo a la ciudad. Se hace necesario aclarar que al referirme a "escena" lo hago de una manera más bien referencial ya que en estricto rigor, en este filme, no podemos aplicar las nociones tradicionales con las que opera el cine, ya que hasta estas mismas nociones son deconstruidas. De esta manera, la definición de "escena" en tanto bloque de acción dramática asentado en una idea que las más de las veces le da coherencia al relato para avanzar en el trayecto de la historia hacia el desenlace, no es aplicable en esos términos al largometraje, en la medida que no hay una idea que dé coherencia y cohesión interna al relato, sino por el contrario, hay mayormente elipsis que dejan grandes lagunas en el devenir de la historia.

La secuencia que describe la trayectoria de Daniel SS podría resumirse en los siguientes términos: río Maipo-centro-población-arrabal. A través de cada uno de estos espacios el protagonista va transitando y buscando, como él dice, una "nueva oportunidad" que nunca se materializa.

13 Esposa de Ricardo Lagos Escobar, presidente de Chile entre los años 2000 y 2006. 
La identidad del protagonista no consigue afincarse en un rol predeterminado, ya que está constantemente desplazándose y asumiendo nuevos roles en función de la necesidad del momento: Daniel SS manipula su identidad a su antojo ya que él es ante todo un manipulador. Eso está en el trasfondo de la propuesta de Sepúlveda, lo cual se aplica con toda propiedad a la realidad cotidiana: de la misma manera que un actor asume un personaje cualquiera en un momento dado, cada uno de nosotros configura en la vida real (en el gran teatro del mundo) su propio o sus múltiples personajes.

Pero por otro lado, la actuación misma, en términos del oficio actoral es vista como un vicio del cual carecerían los actores naturales, lo cual los hace más apropiados para romper el pacto ficcional que se propone este filme. Al respecto, es el mismo Sepúlveda el que señala: "siempre he creído que toda la gente actúa. Los personajes que íbamos conociendo nos contaban que alguna vez habían actuado en la escuela, entonces no era tan difícil porque el vicio actoral no estaba tan metido en la vena de ellos"14. Detrás de esta afirmación está también la idea más arriba expuesta, a la cual se le da mayor desarrollo en la segunda película de Sepúlveda, Mitómana: todos a lo largo de nuestra vida representamos distintos roles, actuamos, fingimos ser pero no somos, mentimos. De ahí el título de su segundo largometraje y Daniel SS también participa de esta condición, de esta construcción que es todo sujeto ${ }^{15}$.

Es en este mismo sentido que Daniel SS, según las convenciones de la sociedad y su normatividad rígida, llevaría también la noción de identidad de género al límite, vinculándose sexualmente con el travesti del circo, al cual sin embargo, utiliza de la misma manera que lo hace con su mujer discapacitada. Por lo tanto, la búsqueda del protagonista desencadena una serie de acciones marcadas por un carácter intransitivo que se agotan en el acto mismo de su consumación sin que conduzcan al protagonista a encontrar "algo" o a sí mismo.

Los procedimientos técnicos a los cuales ya hemos hecho mención y que articulan este largometraje implicarían -a pesar de su praxis despojada de toda sofisticación - la inclusión de la meta ficción en el soporte cinematográfico mismo a través del cuestionamiento de la verdad de lo que se muestra. Esto se logra por la fuerte influencia del género documental y ese posicionamiento fronterizo entre lo real y lo ficticio. De esta manera los recursos formales están al servicio y en congruencia con la representación de la identidad como constructo, entendida también como fronteriza y móvil.

14 "José Luís Sepúlveda, realizador de El Pejesapo" (Entrevista). Obtenido el 2 de noviembre en http://www.chileindependiente.cl/entrevista_jlsepulveda.php.

15 "Ser actriz es la capacidad de transformarse, de poder encajar en varias realidades distintas. Es un modo de pertenecer, pero también de no pertenecer" (Cita de Nora Díaz, la actriz interpretada por Yanny Escobar en Mitómana). 
Críticos como, por ejemplo, Luis Horta, han establecido algunas comparaciones en las propuestas desarrolladas por José Luís Sepúlveda en El Pejesapo y El Chacal de Nahueltoro de Littín:

ambas, en diferentes matices, condenan la miseria humana, y la influencia moralista de la sociedad sobre los desposeídos [... Es un cine que resiste el género (se hibrida entre el documental, ficción y falso documental), el objetivo de llenar la sala el primer fin de semana y el estreno con cocktail $[\ldots]$ El solo hecho de negar y resistir, la convierte en una de las películas más ricas que ha pasado por las salas locales (Horta, 2009).

Al referirse Luis Horta, en estos términos, a un "cine de la resistencia" caemos derechamente en el ámbito de la pregunta por lo político que tiene o no este filme. Claramente no hay una finalidad concientizadora, pero eso no implica que podamos despolitizar este filme, por el contrario. Si bien el mundo del pueblo que le daba al cine anterior el sustento para una determinada acción política se ha desintegrado (Aguilar, 2000, p. 144), la política aquí es la micropolítica, de la misma manera que las luchas sociales, en términos de Guattari (2006), son “molares” y “moleculares”.

Es decir, este concepto implicaría la integración al ámbito de lo político de toda una serie de fenómenos (las relaciones sexuales, familiares, laborales, institucionales, clínicas o escolares) que hasta hace no mucho habían quedado excluidos de ella por su presunta pertenencia a la esfera privada. Ahora lo personal, lo mínimo, es también político. De ahí que adquiera sentido la afirmación de Juan Murillo alusiva al carácter político de El Pejesapo: "es un film político (no en el sentido de una molotov arrojada cobardemente a la Moneda, sino como un padre desesperado prendiéndose fuego al cuerpo)" (Murillo, 2008).

Lo político que hay en El Pejesapo podría pensarse desde lo políticamente incorrecto, desde esa capacidad que tiene de violentar al cine mismo y de ofrecernos la mohosa radiografía o la contracara de los valores universales y monumentales sobre los cuales se ha sustentado la sociedad occidental y la sociedad chilena. Todo esto, mediante el tratamiento de ciertos temas para nada nuevos, como son la representación del sujeto popular-marginal, pero desde un nuevo enfoque que se soporta materialmente mediante una serie de recursos técnicos, la puesta en escena ficcional, que pone el acento en el carácter fronterizo de la realidad misma\}

\section{Referencias bibliográficas}

Aguilar, G. (2006). Otros mundos. Ensayos sobre el nuevo cine argentino. Buenos Aires: Santiago Arcos.

Amado, A. (2003). Imágenes del país del pueblo. Confines, 12. 
Amado, A. (2002). Cine argentino Cuando todo es margen. Confines, 11.

Bajtín, M. (1995). Estética de la creación verbal. México, D.F.: Siglo Veintiuno.

Brioso, J. (2007). La carne de Renéo el aprendizaje de lo literal. Revista Iberoamericana, 73(218), 29-49.

Chile Independiente (2007). José Luís Sepúlveda, realizador de El Pejesapo. Extraído el 2 de noviembre de 2013, desde: http://www.chileindependiente.cl/ entrevistas/jose-luis-sepulveda

Derrida, J. (s.f.) Carta a un amigo japonés. Extraído el 10 de diciembre de 2013, desde http://www.jacquesderrida.com.ar/textos/carta japones.htm

Doll, D. (2013). Escapar de los géneros entrando en ellos. Una tendencia del cine latinoamericano actual. Comunicación y Medios, 26, 51-59.

Fernández, J. S. (2002). La novela de formación: una aproximación a la ideología colonial europea desde la óptica del bildungsroman clásico. Madrid: Universidad de Alcalá.

Follain de Figueiredo, V. (2009). Novos realismos e o risco da ficção. Comunicação, mídia e consumo, 6(16), 29-43.

Guattari, F. (2006). Micropolíticas. Cartografía del deseo. Madrid: Traficantes de sueños.

Horta, L. (2009). El pejesapo: cine de resistencia. Extraído el 10 de diciembre de 2013, desde http://cineclubudechile.wordpress.com/2009/09/23/el-pejesapocine-de-resistencia-por-luis-horta/

León, C. (2005). El Cine de la Marginalidad. Realismo sucio y violencia urbana. Quito: Ediciones Universidad Andina. 